\title{
APRESENTAÇÃO
}

\author{
Francisca de $\mathbf{S}$. Miller \\ (UFRN, Brasil) \\ Ellen Fensterseifer Woortmann \\ (UNB, Brasil) \\ Letícia D'Ambrosio Camarero \\ (UDELAR, Uruguai) \\ José Manuel Sobral \\ (UL, Portugal) \\ José Colaço Dias Neto \\ (UFF, Brasil)
}

\section{DOSSIÊ: PESCA ARTESANAL: PRÁTICAS SOCIAIS, TERRITÓRIO E CONFLITOS}

\begin{abstract}
"A Formosa está repleta de casas, mas cadê trabalho, cadê terra para a gente se manter, para trabalhar, para comer, hem? Comer cimento, comer areia e cal, e palha de cana? A gente que é pobre não pode nem dormir de noite, pensando nos trabalhos, pensando nos filhos, como comprar um calçado, pensando como comprar um vestido, um vidro de remédio, sem a gente ter um salário, sem ter um ganho certo... pescaria de rede, dia dá, dia não dá. Tem mês que passa inteirinho que nem peixe pra comer eles pegam... Hoje em dia é tudo comprado, é tudo tão esquisito." Dona Nedina, 43 anos, pescadora de Baía Formosa, em 1997.
\end{abstract}

Diante dos desafios colocados no contexto contemporâneo em torno da discussão sobre a pesca, seus saberes, ambientes e suas transformações, o presente dossiê traz reflexões diversificadas em termos de campos etnográficos realizados por pesquisadores brasileiros e estrangeiros e perspectivas teóricas. O mote das análises aqui apresentadas reside, ao mesmo tempo, no enfrentamento teórico e na evidenciação etnográfica das transformações ensejadas nas práticas e nos modos como diferentes grupos de pescadores e pescadoras têm interpretado e atuado no contexto de seus ambientes e quais são os desafios por eles enfrentados para a reprodução dos modos de vida de suas famílias.

A degradação e/ou o desequilíbrio dos ecossistemas, a contaminação química ou as disputas por território para implementação ou execução de grandes empreendimentos socioeconômicos, acabam por inviabilizar práticas tradicionais de extração, coleta, captura e manejo de recursos naturais que, como sabemos, são a base para a reprodução social de um grande número de habitantes das regiões litorâneas, alagadiças e ribeirinhas do Brasil. Apenas para citar o cordão litorâneo do nordeste brasileiro, as assim designadas comunidades tradicionais vêm sofrendo grandes impactos do turismo, da carcinicultura, das salinas, das usinas eólicas e agora, tal como observado neste ano de 2019, com a contaminação das águas oceânicas e de parte extensa de suas praias pelo maior derramamento de óleo em território (marítimo) nacional de que se tem notícia.

De acordo com o Instituto de Desenvolvimento Sustentável e Meio Ambiente no Rio Grande do Norte (IDEMA), até o dia 5 de novembro de 2019, já eram 249 locais de 92 municípios, dos 9 estados do Nordeste: Alagoas, Bahia, Ceará, Maranhão, Paraíba, Pernambuco, Piauí, Sergipe e Rio Grande do Norte. 
Todos esses estados, desde o fim de agosto, afetados pelas manchas de óleo. Teme-se que o óleo atinja inclusive as praias do Sudeste. Ao menos 12 Unidades de Conservação, totalizando uma área de mais $2.100 \mathrm{~km}$ atingida por manchas de óleo. Nestas áreas encontram-se importantes ecossistemas, tais como restingas, recifes de coral e manguezais, que abrigam boa parte da riqueza da biodiversidade do litoral. Associados a estes ecossistemas, existem um enorme contingente de famílias que constituem comunidades tradicionais (pescadores e pescadoras, jangadeiros, quilombolas, marisqueiras e marisqueiros, catadores e catadoras de caranguejo) que dependem - exclusivamente, muitas vezes - dessas áreas e de seus recursos para a sua reprodução material, simbólica e econômica, seja na pesca ou no turismo comunitário. A segurança alimentar, a renda, o lazer, o turismo e, sobretudo, o ambiente encontram-se drasticamente ameaçados.

Além de grande impacto socioambiental, o derramamento de óleo já causa enormes impactos econômicos, tendo em vista a importante rota de turismo atingida, que fomenta a economia nacional. O nordeste brasileiro é reconhecido mundialmente por suas belezas naturais, proporcionadas especialmente, pelas belas praias e recifes de corais que possui. Setores de grande importância econômica vinculados ao turismo, como hotéis e pousadas já mostram preocupação com a chegada do verão e a falta de agilidade por parte do governo federal em administrar este desastre.

Este grave crime ambiental traduz a vulnerabilidade da zona costeira brasileira diante de ações humanas que envolvem a exploração desordenada de recursos naturais, especialmente aquelas que envolvem a contaminação dos mares e seus ecossistemas.

Se este é um crime divulgado pela mídia nacional e internacional, há outros crimes ambientais "silenciosos", pouco mencionados pela mídia que atingem especialmente os mangues, estuários e o "mar de dentro", espaços de gênero feminino por definição. Ao escoar os esgotos urbanos, detritos industriais e da agroindústria nesses espaços, as atividades e a saúde das mulheres dos pescadores são postas em risco (WOORTMANN, 1992).

As áreas de manguezais da costa nordestina que muitas vezes são apropriadas de forma comunitária estão sendo contaminadas pelo óleo inviabilizando a coleta de mariscos, lagostins, entre outros frutos do mar, atividade realizada pelas pescadoras que garante a subsistência, sobretudo em dias em que os homens não podem sair ao mar por causa do mau tempo (MILLER, 2010).

De todo modo, se o Poder Público tem dado pouca atenção para questões socioambientais - entre outras - que envolvem a pesca artesanal no Brasil, pelo menos, do ponto de vista de várias áreas de conhecimento acadêmico, científico e tecnológico a atividade tem mobilizado a atenção e empreendimentos de investigação. Por um lado, devido às suas características peculiares no quadro das profundas transformações pelas quais vem passando não só o setor primário, mas toda a economia brasileira. Por outro lado, pelos problemas que derivam de sua coexistência com as estruturas metropolitanas em intensiva expansão, os assentamentos de pescadores artesanais têm permitido uma reflexão sistemática e frutífera sobre as questões suscitadas pelo processo de mudança social, algumas delas expostas neste dossiê.

Temas como o direito consuetudinário, o conhecimento naturalístico, o manejo dos ecossistemas, bem como as formas de organização dos povoados pesqueiros; reconhecimento social do papel da mulher na pesca; os conflitos suscitados pelos diferentes agentes sociais envolvidos com a atividade, de modo direto ou indireto, são algumas das dimensões sobre as quais se têm concentrado os interesses de pesquisa, nas últimas décadas, tanto no Brasil como em outros 
contextos nacionais. Chama atenção, no entanto, no conjunto de etnografias sobre o tema, algumas características peculiares às estruturas de produção em contextos empíricos nos quais se desenvolvem a pesca artesanal, bem como o circuito de distribuição do pescado.

Pescadores artesanais se caracterizam como agentes de uma economia cuja estrutura é notadamente marcada pela imprevisibilidade em relação aos resultados da produção. O peixe, a princípio, é um recurso invisível e, em geral, encontra-se em constante movimento. A captura, portanto, depende da conjugação de sofisticadas técnicas pesqueiras tradicionais compartilhadas entre os oficiantes que são conjugadas como um refinado conhecimento acerca do ecossistema, bem como das espécies aquáticas. Ainda que as pesquisas apontem para a diversidade de ambientes marinhos ou de águas interiores (tais como rios, lagunas e estuários) e para as diferentes técnicas de captura, a problemática em torno da imprevisibilidade do recurso é uma realidade vivida por pescadores artesanais de localidades variadas. Face a esse quadro de instabilidade da pesca masculina, no dizer de uma esposa de pescador de Rio do Fogo: "peixe, dia dá, dia não dá". $\mathrm{O}$ aporte do trabalho feminino, o invisibilizado produto da roça feminina é imprescindível para garantir a segurança alimentar da família, e destarte, do grupo como um todo.

Somadas, ainda, à pressão de diversas atividades econômicas de grande monta - tais como a indústria petrolífera, já citada no início desta Apresentação -, essa característica levanta uma série de questões relevantes para a investigação, algumas das quais também tratadas nas pesquisas aqui reunidas e que provocam o leitor a pensar como grupos de pescadores artesanais e "povos tradicionais", tomados de um modo geral, criam estratégias singulares e criativas de relação com ambiente para, a partir delas, reproduzirem seus modos de vida.

Os trabalhos compilados neste dossiê, portanto, fornecem uma visão geral teórica conceitual - baseada, antes de tudo, em vultosos investimentos de pesquisa empírica - sobre povos e comunidades costeiras no Brasil e em outros contextos nacionais. As contribuições também exibem uma aproximação às várias epistemologias ecológicas existentes nos espaços marítimos costeiros, nas quais se combinam formas de conhecer, gerenciar e disputar.

O texto de Patrícia dos Santos Pinheiro e Aline Maria Pinto da Paixão, intitulado "QUANDO A DESTERRITORIALIZAÇÃO VEM DO RIO: A POLUIÇÃO DO RIO GRAMAME NA COMUNIDADE QUILOMBOLA DE MITUAÇU, PB", que abre esse dossiê da pesca, oferece ao leitor uma análise das ressignificações e adaptações da comunidade quilombola de Mituaçu, na área rural do município do Conde (PB), localizada na Bacia do rio Gramame, estado da Paraíba. A Bacia do rio Gramame, é uma das principais fontes de abastecimento da Grande João Pessoa e também de onde muitos ribeirinhos e quilombolas tiram seu sustento. No entanto, como o que se dá com inquietante frequência em todo Brasil de conflitos e eventos que têm na questão ambiental um importante componente, as modificações no rio Gramame causadas pelas cargas de poluição recebidas continuamente se somam a esse cenário já preocupante. Trata ainda das práticas criativas e memórias, a conformação de sistemas complexos de conhecimento tradicional que se reinventam diante das mudanças que experimentaram.

Por sua vez, o estudo "HIDROELÉTRICAS NA AMAZÔNIA BRASILEIRA: CONSIDERAÇÕES SOBRE OS IMPACTOS NA PESCA ARTESANAL NOS RIOS XINGU (PARÁ) E ARAGUARI (AMAPÁ)" de Christian Nunes da Silva, Vicka de Nazaré Magalhães Marinho, Laís Melo Lima, Ricardo Ângelo Pereira de Lima, Cristiano Quaresma de Paula, Gracilene de Castro Ferreira, Adria de Melo Rosa e Viviane Nunes da Silva Caetano, discute de 
maneira conceitual e de uma abordagem empírica, como a implantação das Usinas Hidroelétricas (UHE) nos rios Xingu e Araguari (Amazônia-Brasil) vem impactando o desenvolvimento da atividade pesqueira, afetando drasticamente a produção e reprodução dos pescadores. Os impactos têm reflexo na perda de territórios de pesca, diminuição da captura dos recursos pesqueiros e aumento de conflitos entre pescadores e demais usuários que praticam a pesca no contexto amazônico.

O artigo de Gabriel Calil Maia Tardelli "DEMARCANDO FRONTEIRAS MORAIS: UMA ANÁLISE DA CATEGORIA OLHO GRANDE EM SITUAÇÕES DE CONFLITO", traz Olho grande enquanto uma categoria acusatória, e ao mesmo tempo, um mecanismo de controle social. $\mathrm{O}$ autor analisa algumas situações sociais nas quais essa categoria é acionada, de modo a tentar compreender os conflitos e as fronteiras morais que são demarcadas na praia por pescadores que exercem diferentes artes de pesca e por barraqueiros, homens e mulheres que vendem ali comidas e bebidas, entre os pescadores da Praia de Piratininga em Niterói (RJ).

O estudo realizado por Inti Raymi Clavijo, Leticia D'Ambrosio e Viviana Cuberos intitulado "TERRITORIALIDADES, CONHECIMENTOS, TRANSFORMAÇÕES E CONFLITOS EM UM ESTUDO DA PESCA ARTESANAL EM LAGUNA GARZÓN, URUGUAI" apresenta alguns aspectos das territorialidades, os conhecimentos, as transformações e os diversos conflitos observados em torno da pescaria artesanal da Laguna Garzón em Uruguai. De acordo com a autora, a partir da pesquisa etnográfica, têm sido reveladas as diferentes formas de categorização e significação da lagoa, o oceano, a barra e o seu entorno, que dão conta do conhecimento gerado nas práticas da localidade. Através das diferentes interlocuções com os pescadores da zona e outros atores sociais, revela-se uma rede discursiva que expõe diferentes elementos que caracterizam uma pescaria detentora de algumas particularidades no Leste do território uruguaio. As diferentes interlocuções articulam variados espaços entre o político e o jurídico, assim como os conhecimentos ecológicos locais e os saberes tradicionais dos povoadores em relação à dinâmica médio-ambiental da área. A territorialidade nativa e as formas de georeferenciamento na lagoa vinculam-se à mobilidade e às características das espécies capturadas, assim como a conexão da água doce e salgada com o espaço oceânico.

O artigo de Stella Maris Nunes Pieve, Gianpaollo Knoller Adomilli e Raizza Costa Lopes intitulado "PESSOAS, PEIXES, PLANTAS: SABERES E TERRITORIALIDADES ENTRE PESCADORES DA LAGOA MIRIM, RIO GRANDE DO SUL" trata dos saberes de comunidades pesqueiras da Lagoa Mirim, localizada na região costeira do extremo sul do Rio Grande do Sul, privilegiando sua relação com o território e suas formas de viver e pensar através da relação com o ambiente. A partir de dados etnográficos, as autoras agregam a discussão sobre territorialidade e saberes, este último, em especial, sobre peixes e plantas, refletindo sobre essas questões a partir de uma perspectiva do conhecimento, compreendida nos saberes e fazeres nativos e ambiental, compreendida no âmbito da territorialidade.

O artigo seguinte, de autoria de Luênia Kaline Tavares da Silva e Francisca de Souza Miller, "PESCA ARTESANAL NO LITORAL SUL POTIGUAR: PERFIL SOCIOECONÔMICO, DIFICULDADES E PERSPECTIVAS(RN)", apresenta o perfil socioeconômico dos pescadores e marisqueiras que vivem nas comunidades de Patané e Camocim, localizadas no município de Arez/RN, litoral sul do Rio Grande do Norte. A pesquisa configura-se como base de análise em um contexto de mudanças socioambientais nos últimos anos, visto que as duas comunidades pesquisadas realizam a pesca no estuário da Lagoa de Guaraíra. Os resultados indicaram que os entrevistados têm idade entre 40 a 60 
anos, possuem apenas o nível de ensino fundamental incompleto, são casados, têm filhos, sobrevivem com um rendimento mensal menor do que um salário mínimo e não recebem o seguro desemprego. Dentre as principais dificuldades encontradas na execução de suas atividades constam a ausência de uma sede para a Colônia de Pesca e a ausência de uma fábrica de beneficiamento para o peixe/marisco. Diante dessa conjuntura, a atividade pesqueira se desenvolve em meio a entraves técnicos, burocráticos e financeiros, em que a necessidade cotidiana de homens e mulheres é o fator determinante na disposição de continuar trabalhando na Lagoa de Guaraíra.

Em seguida, no estudo realizado por Paulo Gomes Almeida Filho, intitulado "PESCA, POLÍTICA E PARENTESCO: Organizações produtivas e processos de familiarização em coletivos de pescas potiguares", o enfoque é no papel conferido ao parentesco por coletivos de pesca artesanais e industriais do litoral potiguar. Através dos dados coletados, o autor mostra como o parentesco é construído nesse universo social e a maneira como ele estrutura a organização produtiva. Discute ainda como o conflito envolvendo as organizações políticas da pesca em São Miguel do Gostoso localizada no litoral norte do Rio Grande do Norte resultou na criação de uma Associação de pescadores mais afinada à organização política tradicional onde as relações de parentesco são centrais.

O trabalho de Flávio Bezerra Barros, Noemi Sakiara Miysaka Porro, Anny da Silva Linhares e Ciro de Souza Brito, intitulado "A TRADIÇÃO DA PESCA NO TERRITÓRIO SESMARIA DO JARDIM (MARANHÃO): CONFLITOS SOCIOAMBIENTAIS E ESTRATÉGIAS DE MOBILIZAÇÃO”, analisa as práticas e os conhecimentos tradicionais associados à pesca no contexto de conflitos socioambientais envolvendo criadores de búfalos e as comunidades quilombolas de Bom Jesus e São Caetano, ambos localizadas no Território Sesmaria do Jardim, município de Matinha, Estado do Maranhão. Os resultados demonstram como diferentes atores sociais se apropriam de modos distintos dos campos para exercer usos concorrentes. Os pescadores artesanais reivindicam o livre acesso ao campo enquanto recurso de uso comum, para o desenvolvimento de suas práticas sociais no trabalho da pesca associado à conservação dos recursos e da natureza. Criadores de búfalos e piscicultores, numa outra lógica, impõem a privatização dos campos, através da implantação de cercas elétricas e açudes artificiais para criação de peixes exóticos. Concluímos que a pesca artesanal dos quilombolas se constitui de práticas e conhecimentos tradicionais e, acima de tudo, é construída por processos de resistência através de direitos definidos num campo de forças políticas.

O artigo "KAWSAK SACHA-SELVA VIVIENTE: PERSPECTIVAS RUNAS SOBRE CONSERVACIÓN", de Marina Ghirotto Santos, Daniel Santi, tem como objetivo descrever e analisar em que consiste a categoria de "conservación" do território do Povo Originário Kichwa de Sarayaku, localizado na Amazônia equatoriana, a partir de sua proposta denominada Selva Viviente o Kawsak Sacha (em espanhol e kichwa, respectivamente) e práticas cotidianas, como a pesca.

O estudo realizado por Paula Regina de Oliveira Cordeiro, intitulado "A DISPUTA ENTRE O TERRITÓRIO TRADICIONAL QUILOMBOLA-PESQUEIRO DE RIO DOS MACACOS E O TERRITÓRIO MILITARIZADO DA

MARINHA DO BRASIL", é uma tentativa de sistematizar as práticas espaciais dos(as) quilombolas-pescadores(as) de Rio dos Macacos, bem como da Marinha do Brasil. Investigar e recuperar os principais elementos e acontecimentos jurídicos-técnicos-políticos que envolvem o conflito. Ao passo que as práticas espaciais são narradas, as cartografias vão aparecendo materializando dois territórios: o território quilombola-pesqueiro do Quilombo Rio dos Macacos, repleto de memórias, sonhos, sentimentos e sentidos e o território militarizado, que tenta 
se impor ao longo do tempo. A solução do conflito territorial e a preservação do território tradicional têm relação direta com o acesso a políticas públicas e à regularização fundiária completa do território, significando que não apenas os espaços de moradia devem ser considerados, mas também os usos tradicionais o que inclui o pleno acesso compartilhado dos cursos hídricos, incluso o Rio dos Macacos e das áreas de agricultura e extrativismo.

Boa leitura!

\section{BIBLIOGRAFIA}

COLAÇO, José. Quanto Custa Ser Pescador Artesanal? Etnografia, relato e comparação entre dois povoados pesqueiros no Brasil e em Portugal. Rio de Janeiro: Garamond, 2015.

COLAÇO, José. Pesca é Coisa de Mulher, Sim Senhor! Algumas reflexões sobre o papel da mulher na atividade pesqueira no Brasil e em Portugal. In: MARTINEZ, Silvia; HELLENBRANDT, Luceni. (org.). Mulheres na Atividade Pesqueira no Brasil. 1 ed. Campos dos Goytacazes: Eduenf, 2019, v. 1, p. 309-332, 2019.

GOVINDIN, J. L. S.; MILLER, F. S. Impactos Sociais da Agroindústria Canavieira na Comunidade de Pescadores de Baía Formosa (RN). Vivencia (UFRN), v. 1, p. 111 - 122, 2016.

SILVA, L. K. T.; MILLER, F. S. Mudanças socioambientais: o caso da pesca artesanal no Complexo Lagunar Bonfim Guaraíba/RN, Brasil. In: SEGATA, Jean et al (org.). Populações tradicionais, ambientes e transformações. Natal: EDUFRN, 2018, 1. ed. 260 p. NATAL: EDUFRN, 2018, v. 1, p. 171-194.

MILLER, F. S. Impactos produzidos por atividades antrópicas nas atividades de pesca e coleta: o caso de algumas comunidades de pescadores do Rio Grande do Norte. In: ADOMILLI, G; CARRÑO, G. D’AMBROSIO, L.; MILLER, F.S. (org.). Povos e Coletivos Pesqueiros: Estudos etnográficos e perspectivas socioantropológicas sobre o viver e o trabalhar. 1. ed. Rio Grande: Editora FURG, 2010, v. 1, p. 9-16 e 281-295. ISBN:978-85-7566253-3.

WOORTMANN, E. F. Da Complementaridade à dependência: espaço, tempo e gênero em "comunidades pesqueiras" do Nordeste. Revista Brasileira de Ciências Sociais, n. 18, 1992. p. 41-60. 